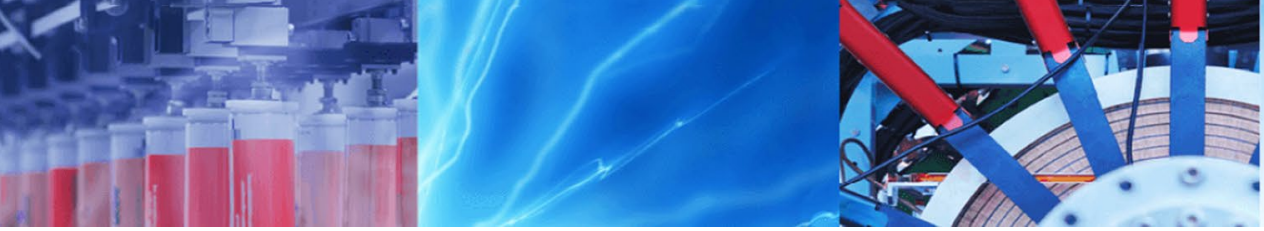

Research Article

\title{
Numerical simulations of a creep rupture damage in Surry PWR primary circuit under TMLB accident
}

\author{
Djillali Saad $^{1}$ (1) $\cdot$ Ahmed Hadjam $^{2} \cdot$ Mohamed Elhadi Boulheouchat $^{3} \cdot$ Tahar Zidi $^{4}$
}

Received: 18 November 2019 / Accepted: 29 January 2020 / Published online: 6 February 2020

(c) Springer Nature Switzerland AG 2020

\begin{abstract}
In the nuclear safety field, the thermomechanical phenomena that occur during an accident in a nuclear power plant (NPP) are of particular importance. During some reactor severe accidents, the decay energy of the core is transferred via the reactor cooling system (RCS) to other parts of this circuit. The associated heatup of RCS structures can lead to pressure boundary failures; with notable vulnerabilities, i.e., the lower head vessel, the pressurizer surge line, the hot leg nozzles, etc. The potential for a primary circuit component rupture is of particular concern because fission products could be released into the environment by such a failure. The risk is higher in-vessel; the relocated debris toward the lower head vessel, following a potential melting of the core, leads to the rupture of the most important protective barrier. Primary circuit structures are subject to the effects of high pressure and high temperature throughout their service life. Such loadings generally lead to creep rupture. This risk is more likely when these structures experience transients or severe accidents. One of the most studied accidents is the station blackout (SBO). SBO without operator actions accident (TMLB' sequence) is considered as one of the most likely scenarios that may threaten the integrity of vulnerable RCS pressure boundaries. In this manuscript, we have evaluated, using the system code RELAP5/SCDAPSIM 3.4, the damage caused by rupture of some structures of the primary circuit of the Surry NPP. The structures analyzed are the surge line, the hot leg nozzles and the lower head vessel. RELAP5/SCDAPSIM 3.4 results indicate that surge line (hot leg) failures will be the first failures in the RCS pressure boundary.
\end{abstract}

Keywords Creep rupture $\cdot$ SBO $\cdot$ TMLB $\cdot$ RELAP5/SCDAPSIM 3.4 $\cdot$ CoupleMeshing $\cdot$ Surry PWR

\section{Introduction}

The tensile properties at room temperature of most structural materials are not very dependent time. Indeed, the results of a tensile test are not very dependent on the loading speed. At high temperature, the tensile performance depends on both the speed of deformation and the time high temperature exposure. At high temperature, new deformation mechanisms may be involved [1]. In a NPP, fuel elements containing uranium or uranium-plutonium (MOX) form the core of a pressurized water reactor (PWR).
The water is heated in contact with the cladding elements and flows at an elevated temperature in a closed circuit: the primary circuit. In a normal operation of a NPP, the temperature of the water circulating in the primary circuit never reaches half the melting temperature of the structural materials $\left(T_{\text {structure }} \ll 0.5 T_{f}\right)$. However, under severe accident conditions, the primary circuit structure temperature of a PWR can easily exceed this threshold $\left(0.5 T_{f}\right)$. In the case of a severe accident (mainly SBO and TMLB) and following the fusion (even partial) of part of the core, the relocated debris to the vessel bottom will rapidly increase

$\triangle$ Djillali Saad, dsaad@usthb.dz | ${ }^{1}$ Mechanical Studies and Nuclear Materials Laboratory, Nuclear Research Center of Birine, BP 180, 17200 Ain-Oussera, Algeria. ${ }^{2}$ Thermal-Hydraulic Laboratory, Nuclear Research Center of Birine, BP 180, 17200 Ain-Oussera, Algeria. ${ }^{3}$ Safety Nuclear Laboratory, Nuclear Research Center of Birine, BP 180, 17200 Ain-Oussera, Algeria. ${ }^{4}$ Atomic Energy Commission, 02 bd Frantz Fanon, BP 399, 16000 Algiers, Algeria. 
the water temperature which is in contact with the wall of the lower head vessel. Under such conditions, the creep rupture is very likely and constitutes the primordial damage even more than the damage caused by the melting of the material, because creep rupture will occur before the temperature of the structure reaches the melting levels of the materials.

A problem of interest in the nuclear power industry involves the response of PWR pressure boundary components under SBO conditions [2]. SBO scenario involves a loss of off-site power, failure of the emergency diesel generators, failure of alternate current $(\mathrm{AC})$ power and the eventual degradation of the reactor coolant pump (RCP) seals under the temperature effect and creep rupture in the surge line resulting in a long-term loss of coolant [3].

In the literature, there are many examples of stationblackout analysis, using severe accident codes to simulate, during the first $24 \mathrm{~h}$, scenarios leading to RCS damage [4]. Vierow et al. have studied $[3,4]$ a TMLB hypothetical scenario of station blackout with a loss of AC power and no recovery of auxiliary feedwater to the steam generators at a 4-loop Westinghouse pressurized water reactor based on Zion. In this study, the authors used MELCOR, MAAP4 and SCDAP/RELAP5 severe accident codes. The event begins with the loss of AC power and steam generator feedwater supply. The turbine trip followed by a reactor scram. The water in the steam generator secondary side boils away, resulting in a loss of heat sink. Natural circulation of hot gasses is predicted to begin when the primary side water level has decreased below the top of the core. Due to the very hot steam coming out of the vessel, there is the potential for excessive heatup of structural components such as hot leg nozzles, the surge lines and steam generator tubes. As a result, a potential failure by creep of these pressure limits is very likely [4]. Larson-Miller creep rupture model is used by these three codes to calculate the thermal transient on the heat structures. Heat structure creep rupture depends on the pressure and temperature history [4]. The variation of the rupture timing by creep is mainly due to the temperature transients of the heat structure. Under such conditions, the creep rupture is very likely and constitutes the primordial damage even more than the damage caused by the melting of the material, because creep rupture will occur before the temperature of the structure reaches the melting levels of the materials.

In this manuscript, we propose a study of evaluation of the creep rupture damage. The event chosen is a station blackout (SBO) with and without mitigation scenario for a 3-loop Westinghouse reactor based on Surry. The Surry NPP is located in Surry County in southeastern Virginia, in the South Atlantic United States. The plant has two tripleloop Westinghouse PWRs which went on-line in 1972 and 1973, respectively. Each reactor produces approximately
800 megawatts of electric power, for a combined plant output of 1.6 GW. In 2003, the Nuclear Regulatory Commission (NRC) extended the operating licenses for both reactors from forty to 60 years. In 2016 its owner announced it intended in due course to seek an extension to 80 years of operation, to 2052 and 2053 [5]. Surry PWR was one of the plants analyzed in the NUREG-1150 safety analysis study.

The RELAP5/SCDAPSIM input deck, which is the basis of our study, has been validated by several works, notably those of Knudson et al. [6] and Siefken et al. [7]. In Knudson et al. work, the authors considered the effect of natural circulation flows that can develop in a reactor cooling system (RCS) during some reactor accidents, transferring the decay energy from the core to other parts of the RCS. Siefken et al. work is a severe accident analysis in order to exercise and evaluate damage progression models in RELAP5/SCDAPSIM 3.3 under conditions typical of those expected in the typical plant severe accident analysis. The severe accident analyzed was a SBO without operator actions.

The original RELAP5/SCDAPSIM input deck does not contain the COUPLE mesh part. Our contribution to the input file, in addition to its adaptation to simulate the severe accidents scenarios considered in the present study, is to generate all the COUPLE mesh part necessary for the execution. The CoupleMeshing program [8] was used in the mesh generation needed for the COUPLE mesh module. In addition, we added the necessary cards to the input file to represent the break initiation in the hot leg and the pump leaks caused by the loss of the seals.

\section{Prediction of creep ruptures resistance in high temperature}

Theoretical models of behavior in creep deformation and creep rupture are not yet sufficiently developed so that we can derive predictions that are sufficiently precise to be used in engineering [9]. It is therefore necessary to refer to reliable experimental data. These experimental data are presented in the form of curves correlating creep stress and stationary creep speed at different temperatures (Fig. 1a). Another representation consists of correlating, at a given temperature, the stress and the creep time for which a certain rate of deformation-or rupture-is reached (Fig. 1b).

It is often necessary to extrapolate these data to times or rates of deformation with difficulty accessible experimentally. For example, it is difficult to determine experimentally the creep stress corresponding to a deformation of $1 \%$ in $10^{5} \mathrm{~h}$, that is to say 11.4 years, in particular if it is of a material that has just been developed. 

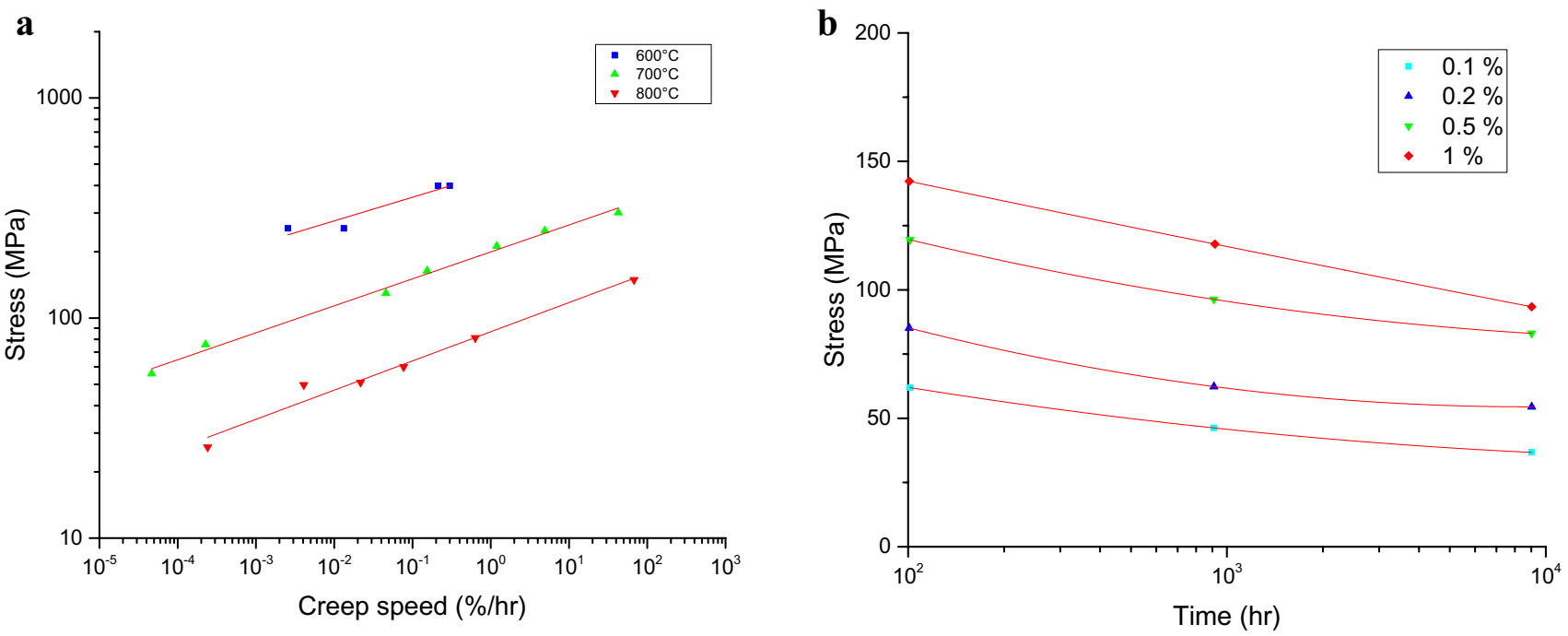

Fig. 1 Creep stress as a function of the: $\mathbf{a}$ creep speed and $\mathbf{b}$ creep time [10]

The extrapolation of the previous curves (Fig. 1) to longer times than those studied experimentally is possible only if it is certain that no microstructural modification occurs between the domain of time explored experimentally and the times toward which one seeks to extrapolate. Indeed, such a transformation would have the effect of modifying the slope of the real curve outside the explored experimentally domain and the extrapolation would be abusive.

Since microstructural transformations usually occur at shorter times for higher temperatures, it is wise to compare the slope of the curve that one wants to extrapolate with the slopes of data curves obtained experimentally at higher temperatures. Based on this hypothesis, Larson and Miller [11] formulated a time-temperature equivalence based on the following reasoning. The stationary flow rate of an alloy intended for use in high temperature is written.

$\dot{\varepsilon}=A e^{-\frac{\Delta H}{k T}}$

In this equation, $\mathrm{A}$ is a constant that is, a priori, dependent on the creep stress and $\Delta \mathrm{H}$ is the activation energy of the mechanism controlling the creep rate. We deduce the expression of the rupture time as a function of temperature.

$\ln t=\ln \frac{\varepsilon}{A}+\frac{\Delta H}{k T}$

From experimental data, Larson and Miller have established that for each of the alloys they study, the plot for different stresses $\sigma$, of $\ln t=f(1 / T)$ imposed strain rate, had the shape of Fig. 2a. Note that in this figure $Q / R$ corresponds to $\Delta H / k$. Still experimentally, Larson and Miller establish that this equivalence relation remains valid when the rate of deformation considered is chosen as the rate of deformation at rupture $\varepsilon_{\mathrm{r}}$. We then obtain a relationship between the rupture time $t_{r}$ and the test temperature at fixed stress. Moreover, for a wide range of alloys, the experimental measurements give $C_{1}$ such that, when $t_{\mathrm{r}}$ is given in hours.

$35<C_{1}<60$

Larson and Miller suggest that the value $C_{1}=46$ could be valid regardless of the alloy being studied. From this time-temperature equivalence, one draws the Larson-Miller parameter which is written.

$P=T\left(\ln t_{\mathrm{r}}+C_{1}\right)$

Larson and Miller then report the experimental data $\left(t_{r^{\prime}}\right.$ $T, \sigma)$ in the reference $(P, \ln \sigma)$ and obtain, for each alloy, a curve that is in the form of two straight segments (Fig. 2b). This curve is called master curve because it represents the superposition of creep rupture curves $\left(t_{r}=f(\sigma)\right)$ to different temperatures, the parameter allowing to modify the time so that the different curves are found on a single curve. Although Larson and Miller try to justify the choice of their representation on the basis of a classical law, their approach, which relies on the compilation of reliable experimental results, remains essentially empirical.

\subsection{Creep rupture model used in RELAP5/SCDAPSIM}

The creep rupture model used by the RELAP5/SCDAPSIM code is based on two different theories: (1) Larson-Miller [11] 

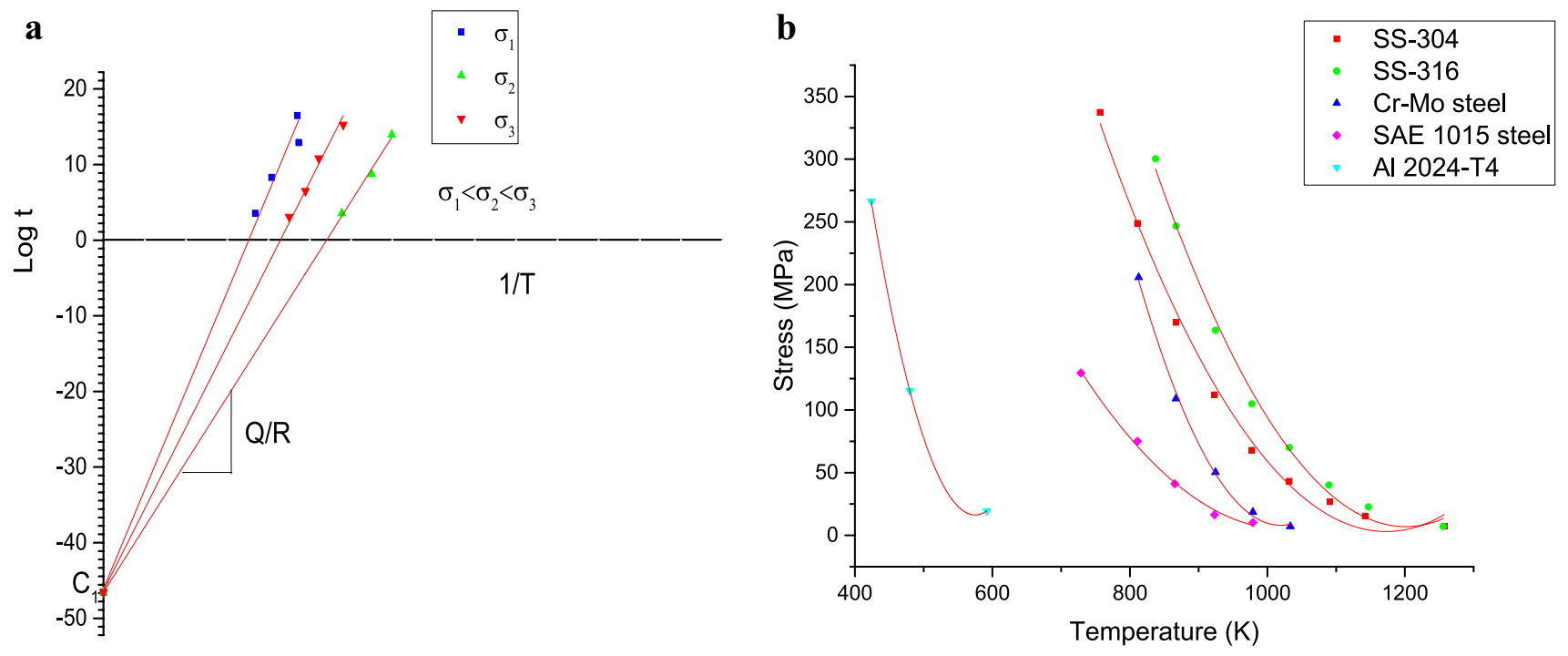

Fig. 2 a Time-temperature equivalence in creep [5] and $\mathbf{b}$ creep rupture for various alloys [11]

and (2) Manson-Haferd [12]. The composition of the material and the applied stresses define the choice of this or that theory. The three most widely used nuclear materials are modeled for creep rupture: (a) carbon steel (CS) A-508 class 2, (b) 316 stainless steel (SS) and (c) Inconel 600. For the last two materials, the Larson-Miller theory is used, while for CS, the choice of the theory is dependent on the level of stress applied. Manson-Haferd's theory is applied for low stresses and Larson-Miller's theory for higher stresses [13].

In Goldhoff's study [14], the criteria for choosing the theory best suited to a material and for a temperature range are presented. On the basis of the results obtained from the creep rupture tests carried out on samples under constant stress and temperature, the criteria of the applicable theory are determined. The tests carried out with a series of stresses and temperatures allow us to draw a family of curves of the log rupture as a function of the temperature and the log rupture time as a function of the reciprocal temperature. The Larson-Miller theory [11] is better suited when the family of curves on a graph of the log rupture time as a function of the test temperature is at a point with a value of $1 / T=0$, where $T=$ temperature in degrees $R$. The Dorn [15] theory is used when the family of curves is parallel. The Manson-Haferd theory [12] is used when the family of curves on a graph of the time of rupture as a function of temperature is found at a point. In order to evaluate creep rupture in a structure, a parameter measuring the damage is calculated for each time step:

$D_{c}(t+\Delta t)=D_{c}(t)+\frac{\Delta t}{t_{r}(t)}$ where $D_{c}(t)$ is the creep damage at time $t, \Delta t$ is the time step $(s), t_{r}(t)$ is the time required for the structure to fail by creep rupture at the current state of temperature and stress (s) and $t$ is the problem time (s).

The state of the structure is evaluated according to the value of $D_{c}$ if it is equal to zero, the structure has not suffered any damage due to creep. If the value is 1 , the structure has failed. The calculation $t_{\mathrm{r}}$ depends on the composition of the material and the applied effective stress in structure $\left(\sigma_{\text {eff }}\right)$. For the three most used nuclear materials, the equation of $t_{r}$ is given in Table 1. In the case of the Surry PWR, the lower head vessel is made using cylindrical forging of CS A-508 class 2 and coated with 304 SS (Fig. 3). Inconel 718 is used for the grid material because of its corrosion resistance and high strength properties. The structural material of pipes for the hot leg nozzles and pressurizer surge line is type 304 SS (Fig. 4).

\section{Surry PWR model description and nodalization}

Figure 3 shows the RELAP5 nodalization of the reactor vessel [2]. The reactor core is modeled by five radial segments and ten axial nodes. In order to model the flow in the lateral direction through the core, the flow channels are connected to its neighboring flow channels by crossflow junctions. The core bypass and the downcomer are represented by separate RELAP 5 control volumes. The core bypass is represented by a RELAP 5 control volume containing five sub-volumes and the downcomer is represented by a RELAP5 control volume with seven sub-volumes. The lower plenum is represented by a two RELAP5 
Table 1 Creep rupture time equations used in RELAP5/ SCDAPSIM [9]

\begin{tabular}{|c|c|c|c|}
\hline Material & Stress range (MPa) & Theory applied & $\begin{array}{l}\text { Creep rupture time } \\
\text { Time (hr) and Temperature (R) }\end{array}$ \\
\hline \multirow[t]{2}{*}{ CS A-508 } & $0<\sigma_{\text {eff }}<96$ & Manson-Haferd & $\begin{array}{l}t_{\mathrm{r}}=10^{\frac{T-1503.69}{P}}+3.499 \\
P=158.233 \log \left(\sigma_{\text {eff }}\right)-255.346\end{array}$ \\
\hline & $\sigma_{\text {eff }} \geq 96$ & Larson-Miller & $\begin{array}{l}t_{r}=10^{\frac{T}{\rho}}-20 \\
P=9603 \log \left(\sigma_{\text {eff }}\right)+46454\end{array}$ \\
\hline \multirow[t]{2}{*}{316 SS } & $0<\sigma_{\text {eff }}<358$ & & $\begin{array}{l}t_{r}=10^{\frac{T}{P}-20} \\
P=-13320 \log \left(\sigma_{\text {eff }}\right)+54870\end{array}$ \\
\hline & $\sigma_{\text {eff }} \geq 358$ & & $\begin{array}{l}t_{r}=10^{\frac{T}{P}-20} \\
P=-64000 \log \left(\sigma_{\text {eff }}\right)+142000\end{array}$ \\
\hline Inconel 600 & $\sigma_{\text {eff }} \geq 0$ & & $\begin{array}{l}t_{r}=10^{\frac{T}{P}-15} \\
P=-11333 \log \left(\sigma_{\text {eff }}\right)+43333\end{array}$ \\
\hline
\end{tabular}

control volumes and the upper plenum by seventeen RELAP5 control volumes.

Figure 4 shows the RELAP5 nodalization of the coolant loop with the pressurizer (loop C) connected to the hot leg. The rest of the loops without pressurizer ( $A$ and $B$ ) were modeled with similar nodalizations of the $C$ loop. The hot leg is represented by five volumes, the cold leg by four volumes, the surge line by three volumes, and the pressurizer by eight volumes. The primary side of the steam generator is represented by eight volumes and the secondary side by twenty volumes. The loop seal is represented by five volumes.

The core consists of $15715 \times 15$ Westinghouse fuel assemblies with an active fuel height of $3.66 \mathrm{~m}$. A SCDAP PWR model is presented for fuel rods and another model for control rods. Each fuel assembly is presented by 204 fuel rods and 21 control rods. The model of the fuel and control rod has been divided into ten axial nodes. A SCDAP control rod component model containing an extremely small quantity of control material is used to represent the water rods in the outermost radial segment. Another model of fuel rod component with an extremely small fuel pellet is used to represent the empty zircaloy guide tubes in the center ring. The reactor core is modeled by a total of ten SCDAP components. The center radial segment is modeled by two fuel rod components. The other four radial segments are modeled by a fuel rod component and a control rod component. The reactor core contains six Inconel spacer grids located at several elevations. A SCDAP model is used to represent these spacer grids.

For the COUPLE mesh part, the RELAP5/SCDAPSIM 3.4 code uses the formatted input. Manual mesh generation for the COUPLE mesh part is very difficult. Not only the establishment of this part is tedious, but also the rest of the formatted entries needed for execution (Material Block, Internal Heat Generation Block, Convection Data Block, etc.) are very difficult to introduce. To remedy this problem, we used the CoupleMeshing program [8]. This tool, very useful, allows us from some unformatted lines (5 lines) containing the data of the geometry and the materials, to generate all the part of the input file of the COUPLE mesh model. The lower head is modeled by an axisymmetric vessel. It has a maximum of 15 nodes in the r-direction and a maximum of 23 nodes in the $z$-direction (Fig. 5). Material modeled by the lower head includes relocated debris, SS, Inconel, CS and coolant. Among these materials, only relocated debris can have an internal heat source. RELAP5 single volume 106 is used for the lower head flow boundary volume. It can hold slumped material during the accident.

The severe accident analyzed in this study is a typical case of SBO with and without mitigation scenarios. The first scenario (scenario \# 1 ) is a TMLB' sequence ( $T$ "transient event", $M$ "failure of the secondary system steam relief valves and the power conversion system", $L$ "failure of the auxiliary feedwater system", $B$ "failure of the electric power to ESFs"). The accident is initiated by loss of off-site power. Diesel generators do not start from where on-site $A C$ power is unavailable. As a result, electric pumps are not supplied with AC power, and steam-driven auxiliary feedwater pumps fail to supply water, which means that decay heat removal through the steam generators cannot be maintained in the long term. RCP seal leaks were among the factors that were considered. Leakage of seals is comparable to a small LOCA occurring at a rate of $1.3 \times 10^{-2}$ / reactor-year [16]. In this study, we considered a typical leak of $1.31 \mathrm{l} / \mathrm{s}$ per pump. Other factors that were considered include RCS depressurization following predicted pressure boundary failures. As the RCS depressurizes during the accident, the RCP loop seals may clear. The combined case (break initiation + leakage) is also considered in this study. The second scenario (scenario \#2) takes into account the possibility of operating, for periods 30,60 and $90 \mathrm{~s}$, the main feedwater (MFW) emergency pumps (diesel generators or steam-driven auxiliary feedwater pumps) in order to recover the auxiliary feedwater to the steam generators. 
Fig. 3 Surry reactor vessel nodalization [6]

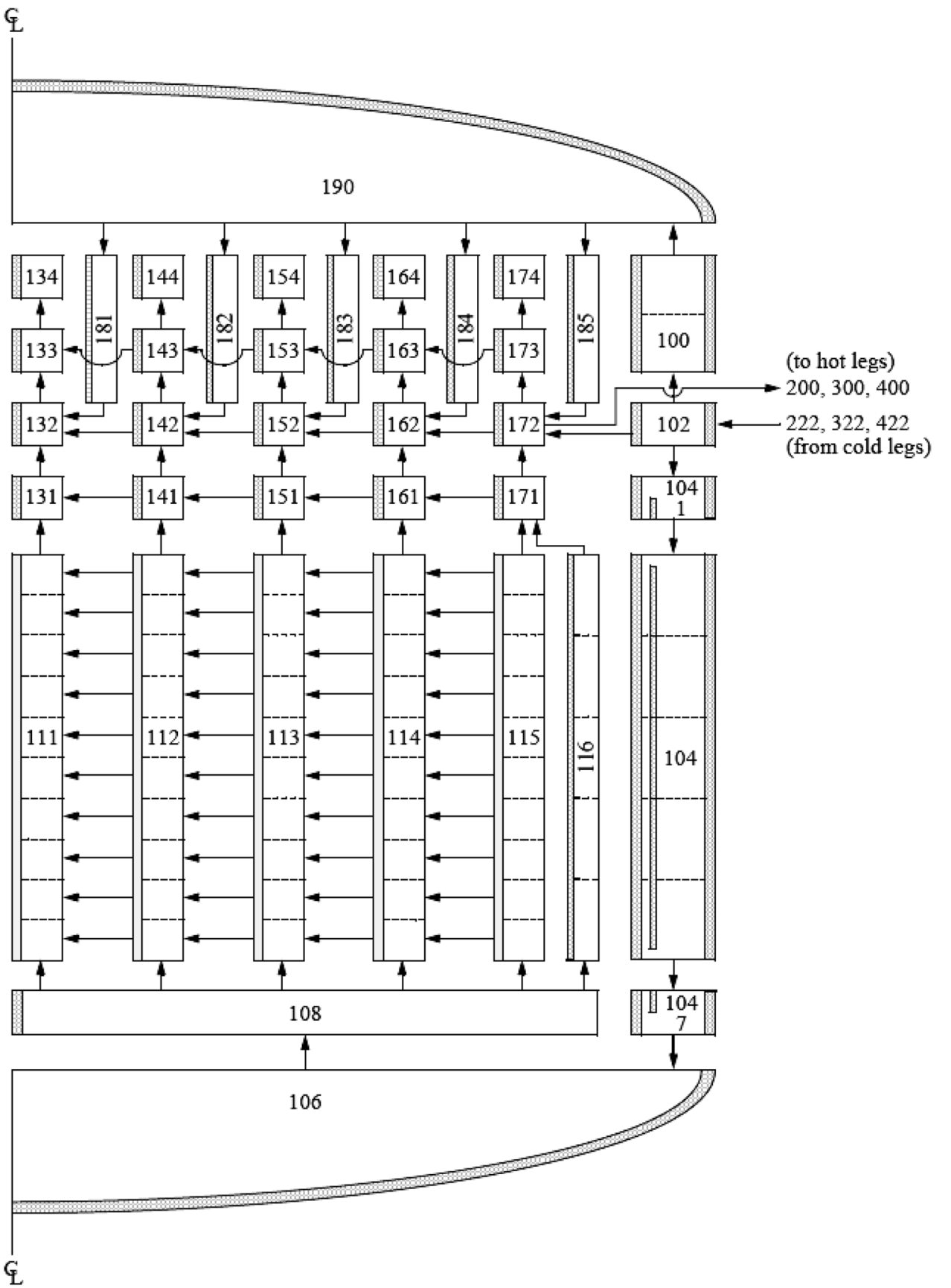

$€$

104

. 


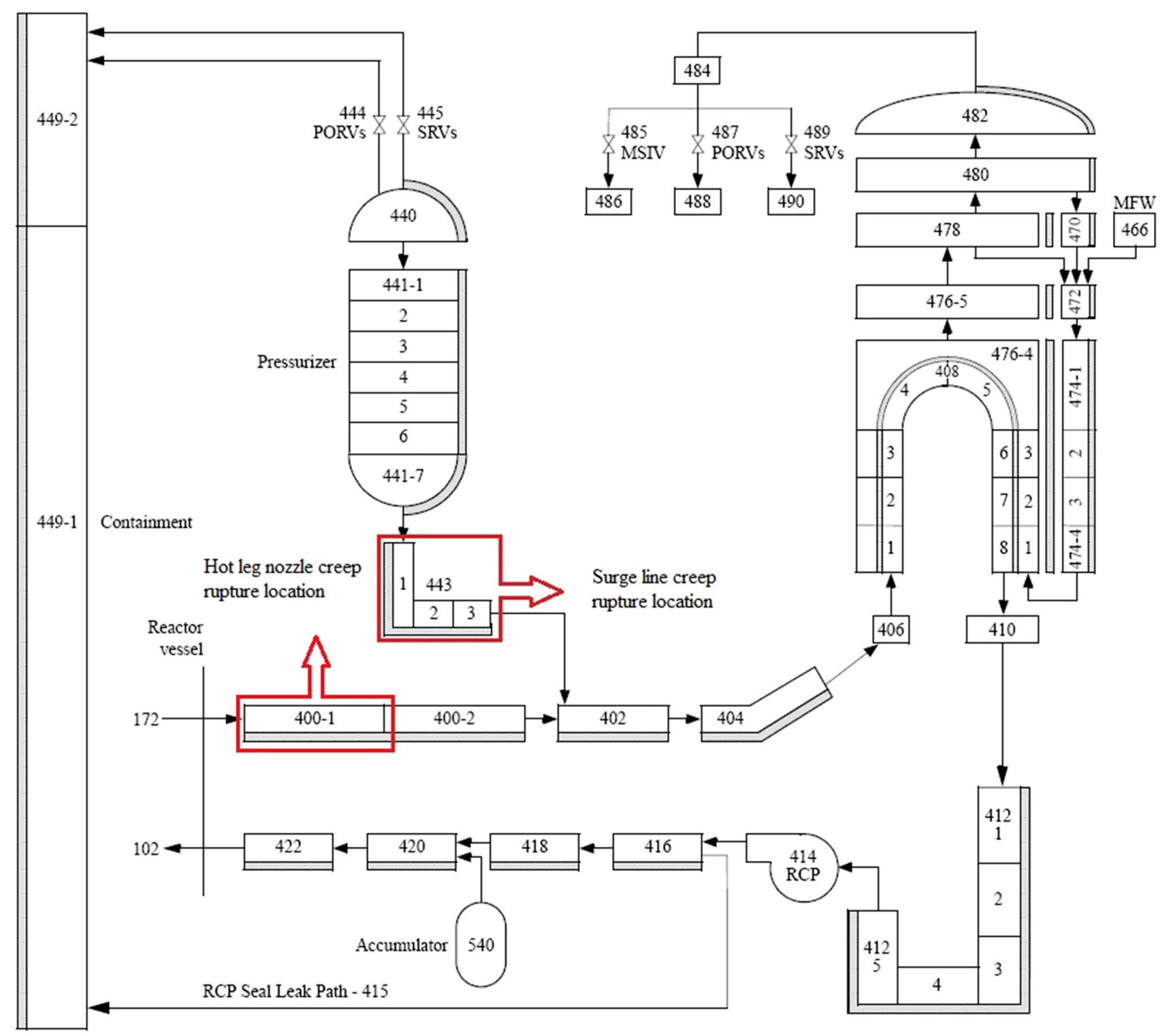

Fig. 4 Surry pressurizer loop nodalization [6]

SG secondary, the (steady state) RCS subcooled margin in this case was essentially maintained. After SG secondary dry out, the heat transfer from the RCS was substantially reduced. With reduced heat transfer to the SGs and the continuous addition of core decay heat, the RCS inventory was ultimately heated to a saturated state. Further addition of decay heat resulted in boiling of the RCS liquid in the core. Therefore, vapor in the pressurizer dome had been vented and liquid was being discharged through the pressurizer PORV. As a result, the volume expansion associated with boiling resulted in a substantial increase in the RCS pressure above the pressurizer PORV set point (Fig. 6). RCS depressurization continues until SG secondary liquid inventories are boiled and released to the atmosphere by
SG SVs. Thereafter, the cooling provided by the heat loss from the system to the containment and the leakage rate of the pump shaft seal is insufficient to remove the RCS heat load. Consequently, the RCS pressure increases to the opening setpoint pressures of the pressurizer PORVs and SRVs, as shown in Fig. 7. The most difficult RCS pressure conditions are encountered when the pressurizer fills with water, as shown in Figs. 6 and 8 [17].

Excessive heating of the core and venting via the PORV pressurizer led to the depletion of RCS inventory. As shown in Fig. 9, the collapsed liquid level fell below the top of the fuel rods by $6850 \mathrm{~s}$. The core uncover was completed at $8300 \mathrm{~s}$, while oxidation of the uncovered core began by around $11,460 \mathrm{~s}$. 

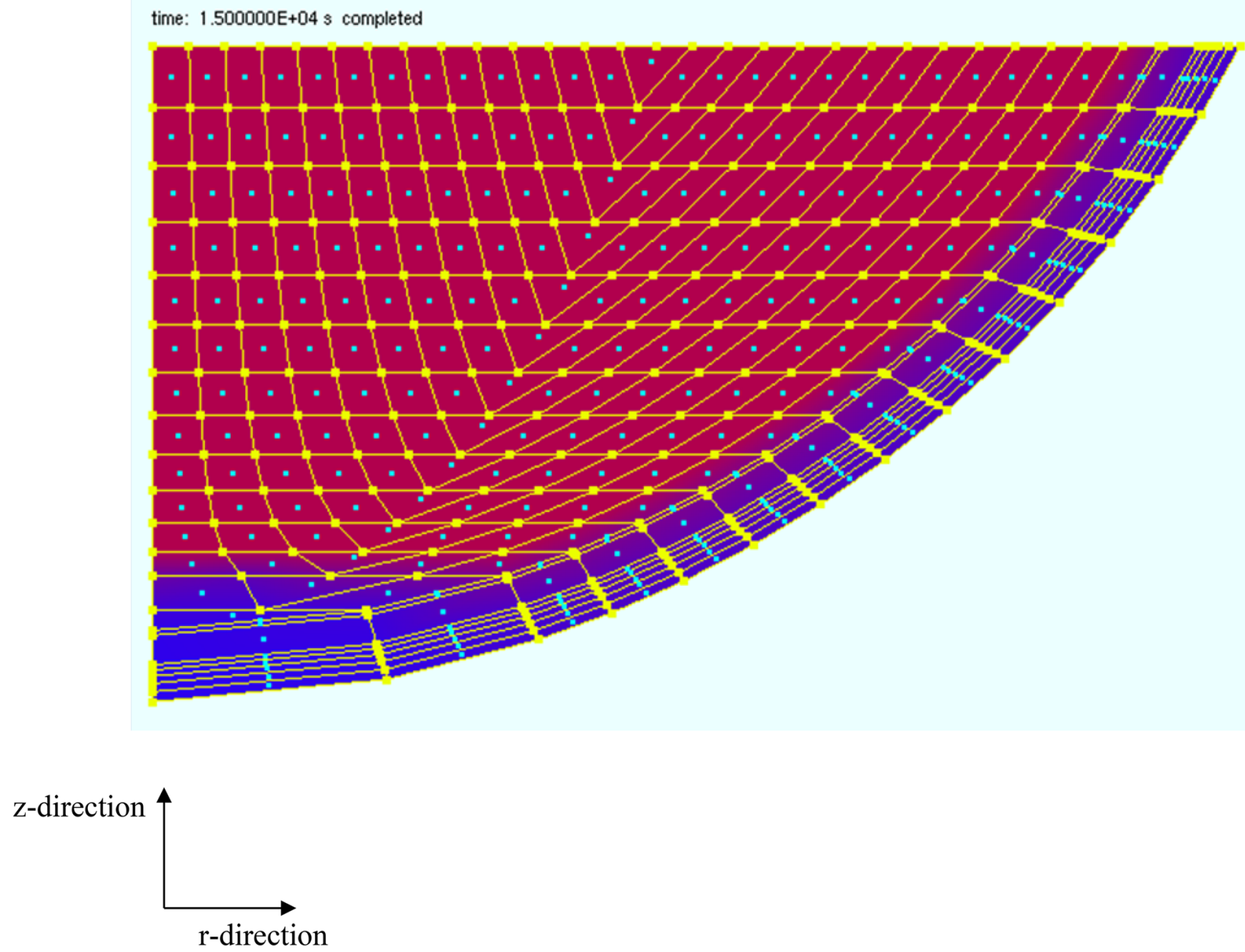

Fig. 5 COUPLE FE mesh used to model the lower head vessel ( 345 nodes and 308 elements)

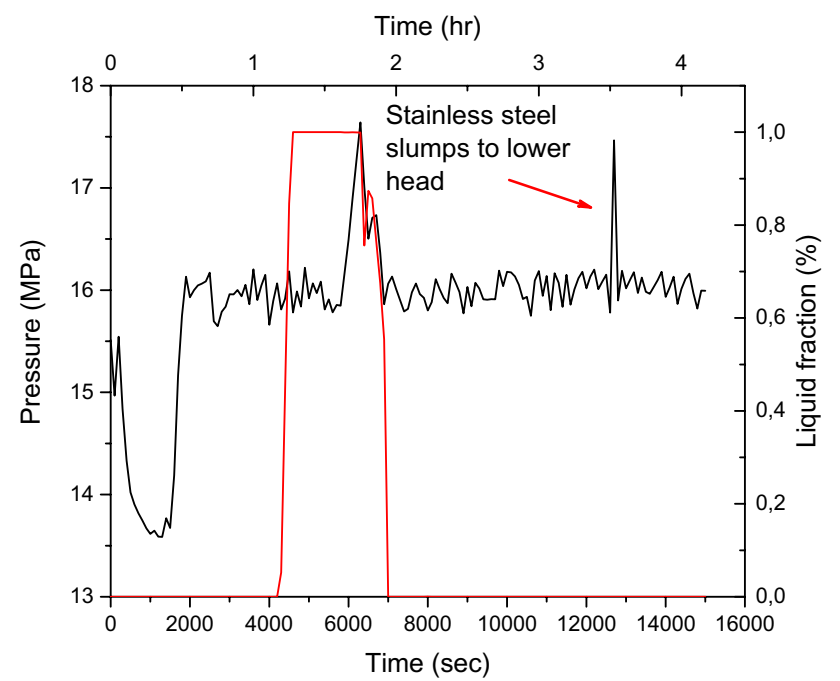

Fig. 6 Pressure and liquid fraction in pressurizer for scenario \#1

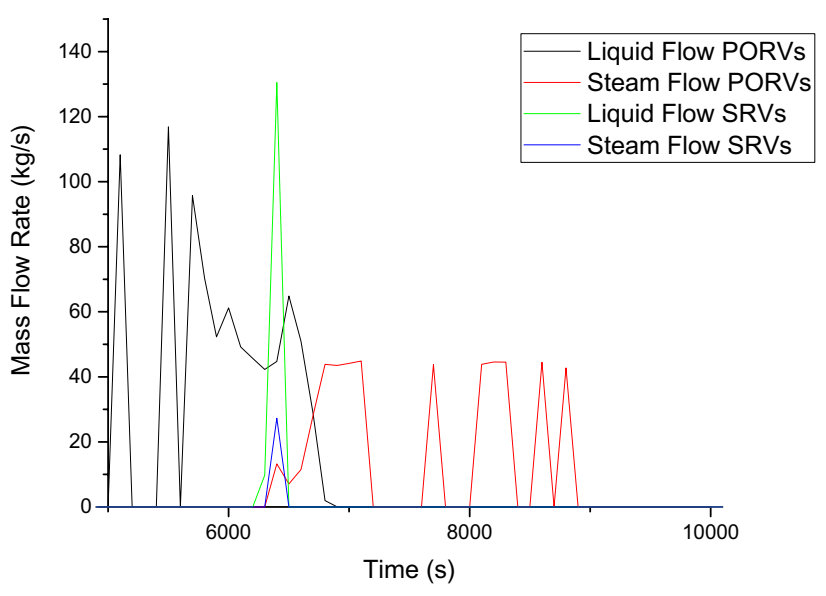

Fig. 7 Mass flow rate of liquid and steam evacuated through PORVs and SRVs

\section{SN Applied Sciences}




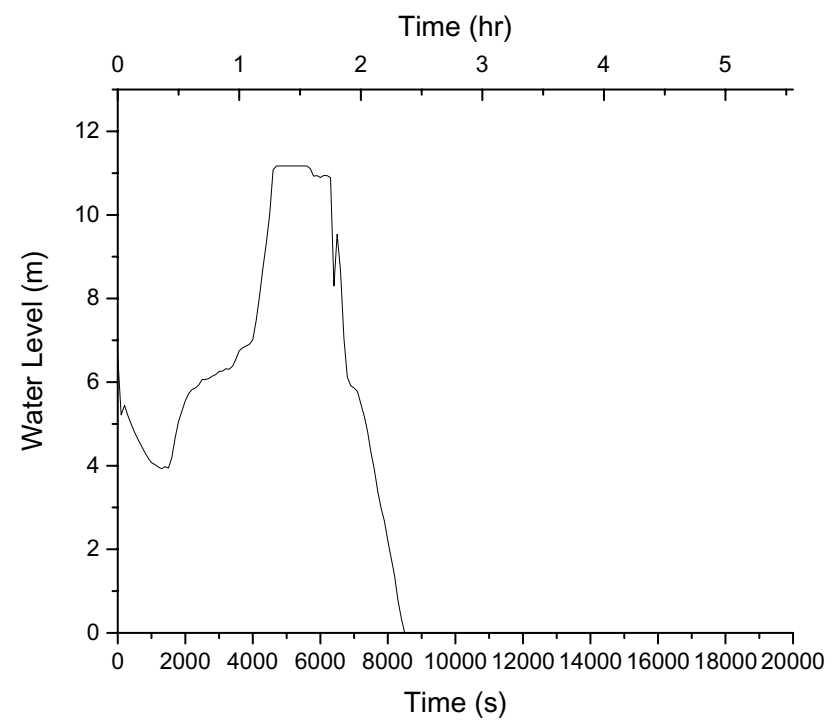

Fig. 8 Pressurizer liquid level

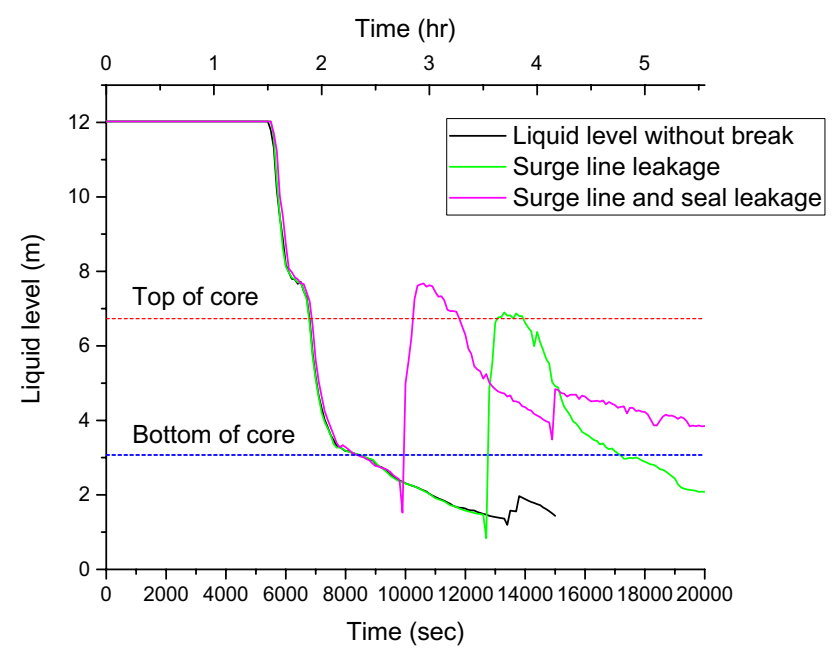

Fig. 9 Reactor vessel collapsed liquid level for scenario \#1

The first failure of the RCS pressure boundary is the creep rupture of the pressurizer surge line at $9800 \mathrm{~s}$ (corresponds to the creep damage term equal to unity), Figs. 10 and 11. This is among the reasons that the modeling of an SBO accident is generally associated with the presence of a break in the RCS circuit. Another phenomenon resulting from this type of accident is the failure of the primary pumps seals caused by the excessive increase in the temperature. Figure 12 shows the evolution of the pressure in the lower head vessel for these two additional factors (with rupture initiation only and rupture initiation with leakage). It is clear that the depressurization of the RCS circuit is faster in the second case (more loss of coolant). This depressurization leads to the priming of the accumulators

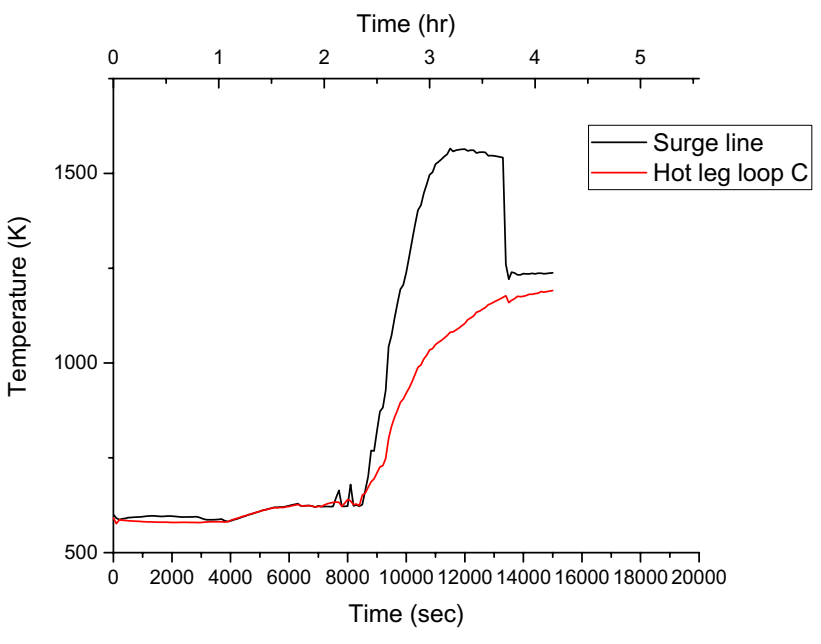

Fig. 10 Primary circuit structure temperature

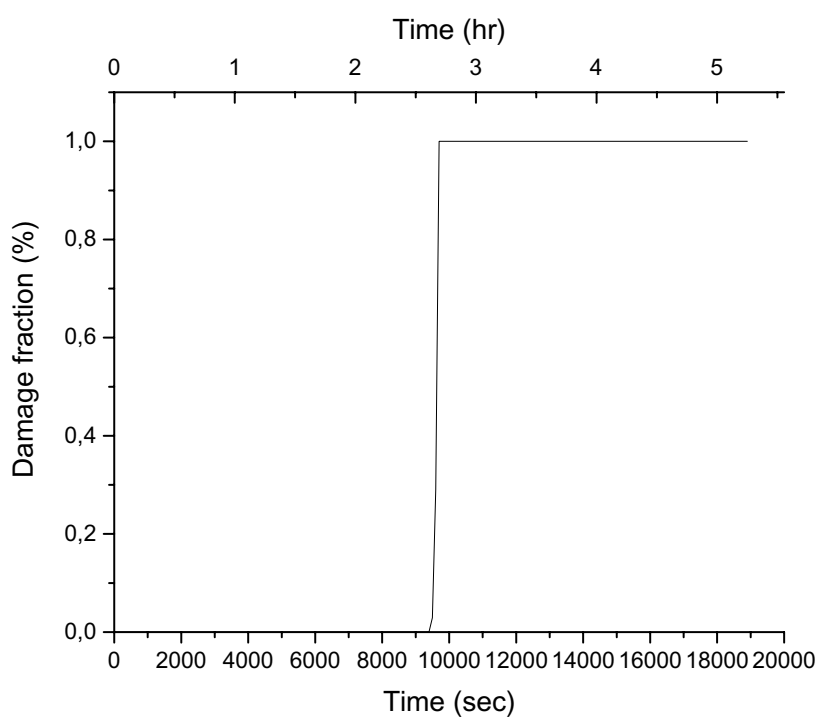

Fig. 11 Damage fraction in the surge line

and makes it possible to have more extra water in the vessel. This saves precious time before the total core uncovery (Fig. 9).

As shown in Fig. 13, hydrogen production will begin after $145 \mathrm{~min}$ (8700 s) of the accident, with a significant increase for the case of break initiation plus leakage.

Creep damage fraction in the hot leg nozzles was significantly higher in the pressurizer loop than in the two other loops, about $0.31 \%$ versus $6.9 \times 10^{-5} \%$, respectively (Fig. 14).

To calculate the in-vessel creep rupture, we use the COUPLE mesh module of the system code RELAP5/SCDAPSIM 3.4. For the preparation of the input for this part, we used the CoupleMeshing program (mesh generation and Data) [8]. We selected nine (09) locations for the calculation 


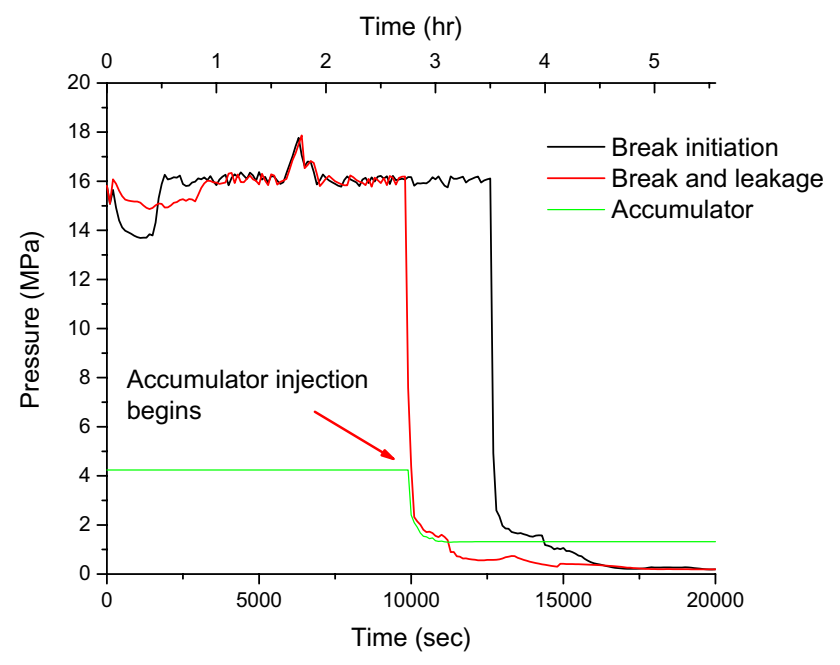

Fig. 12 RCS pressure in the reactor lower head vessel for scenario $\# 1$

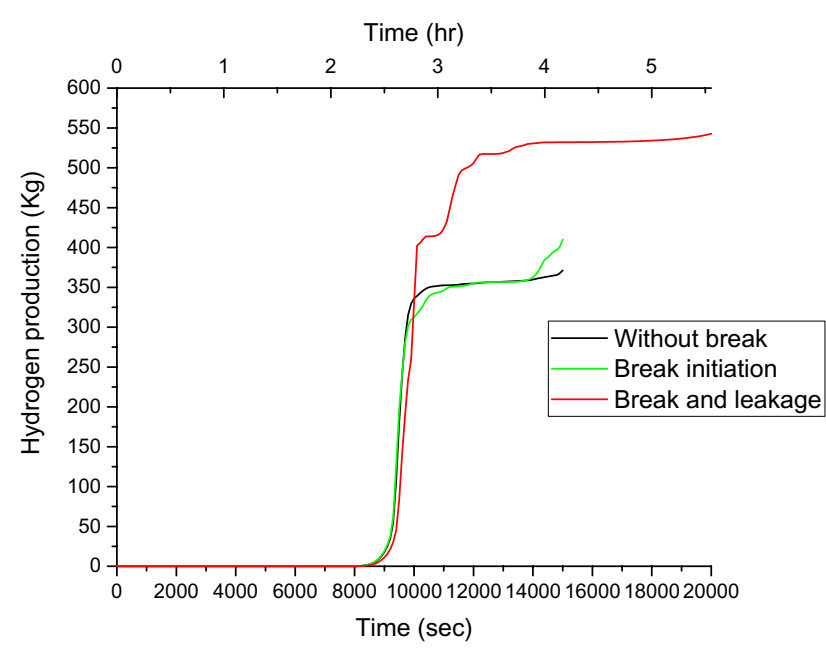

Fig. 13 Integral hydrogen production

of the creep damage factor. The selected locations begin with the lowest to highest zone of the hemisphere forming the lower head vessel (Fig. 15). The melting of the core begins with the center (hot channel); the slumped material thus generated is relocated toward the center of the lower head vessel. Consequently, part of the water remaining in the lower head vessel evaporates and the temperature of this structure increases rapidly. As the mass of debris accumulates, the debris will be spread on the surrounding surfaces. Figure 16 confirms this finding; it is clear that the creep rupture of the lower head vessel starts at $11,400 \mathrm{~s}$ (location \# 1) and ends at 12,600 s (location \# 9).

For scenario \# 2, the emergency water supply system (secondary side), which is responsible for supplying the steam generators in case of loss of electricity (off-site), is able to perform his role for some time. The operation of the

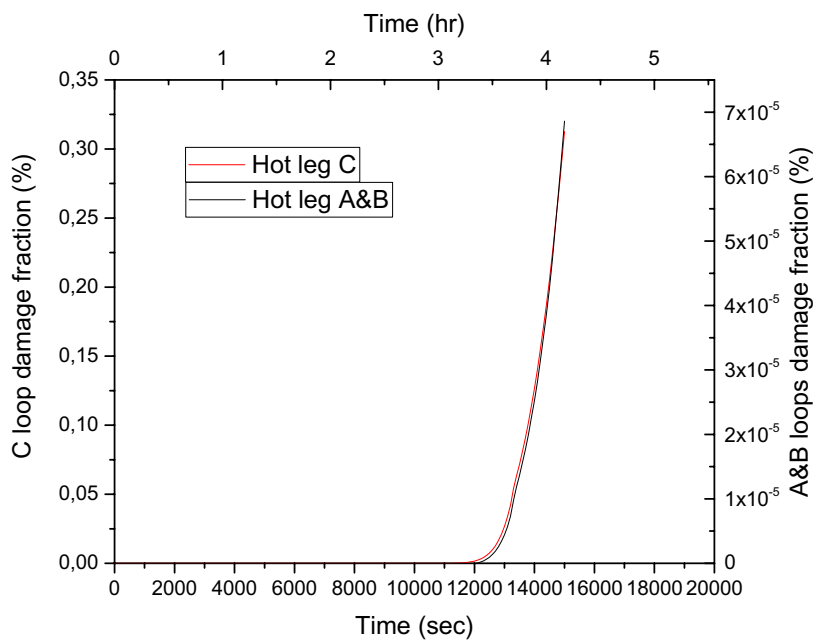

Fig. 14 Damage fraction in the hot leg nozzles

pumps is ensured by the energy supplied by diesel groups or directly by the steam (driven turbine). In this scenario, we tested the SG cooling by the MFW for periods of 30, 60 and $95 \mathrm{~s}$. Figure 17 shows the evolution of the reactor vessel collapsed liquid level for the three periods. The first observation that can be drawn from these results is that a 30 -s operation of these pumps can preserve an hour of recovery of the core. All the phenomena that we have identified in the case of the scenario \# 1 are present for the scenario \# 2, but only with a delay of appearance. If the MFW system continues to perform its function for a period greater than or equal to $100 \mathrm{~s}$, all residual heat from the core will be evacuated.

The loss of $A C$ and $D C$ power is assumed to occur at the start of the SBO simulation. The reactor SCRAM follows with the coast-down of Auxiliary feedwater pumps (AFWPs) and reactor cooling pumps (RCPs) tripped. Feedwater is quickly reduced to zero. Without recovery of power or equipment, the transient proceeds to severe core damage and melting. The accident event sequences for Scenarios \#1 and \#2 are summarized in Tables 2 and 3.

\section{Summary and conclusions}

We have seen in this study that the associated heatup of RCS structures can lead to pressure boundary failures. A number of RELAP5/SCDAPSIM 3.4 analyses were carried out to evaluate, in an operating PWR, the damage caused in the RCS circuit (in and ex-vessel) during TMLB accidents (and their variations). In this analysis, all RCS pressure boundaries were assumed to be defect free with respect to the prediction of pressure boundary failures. Conclusions based on results from the RELAP5/SCDAPSIM 3.4 analyses are summarized below. 
Fig. 15 Considered creep rupture locations in the lower head vessel
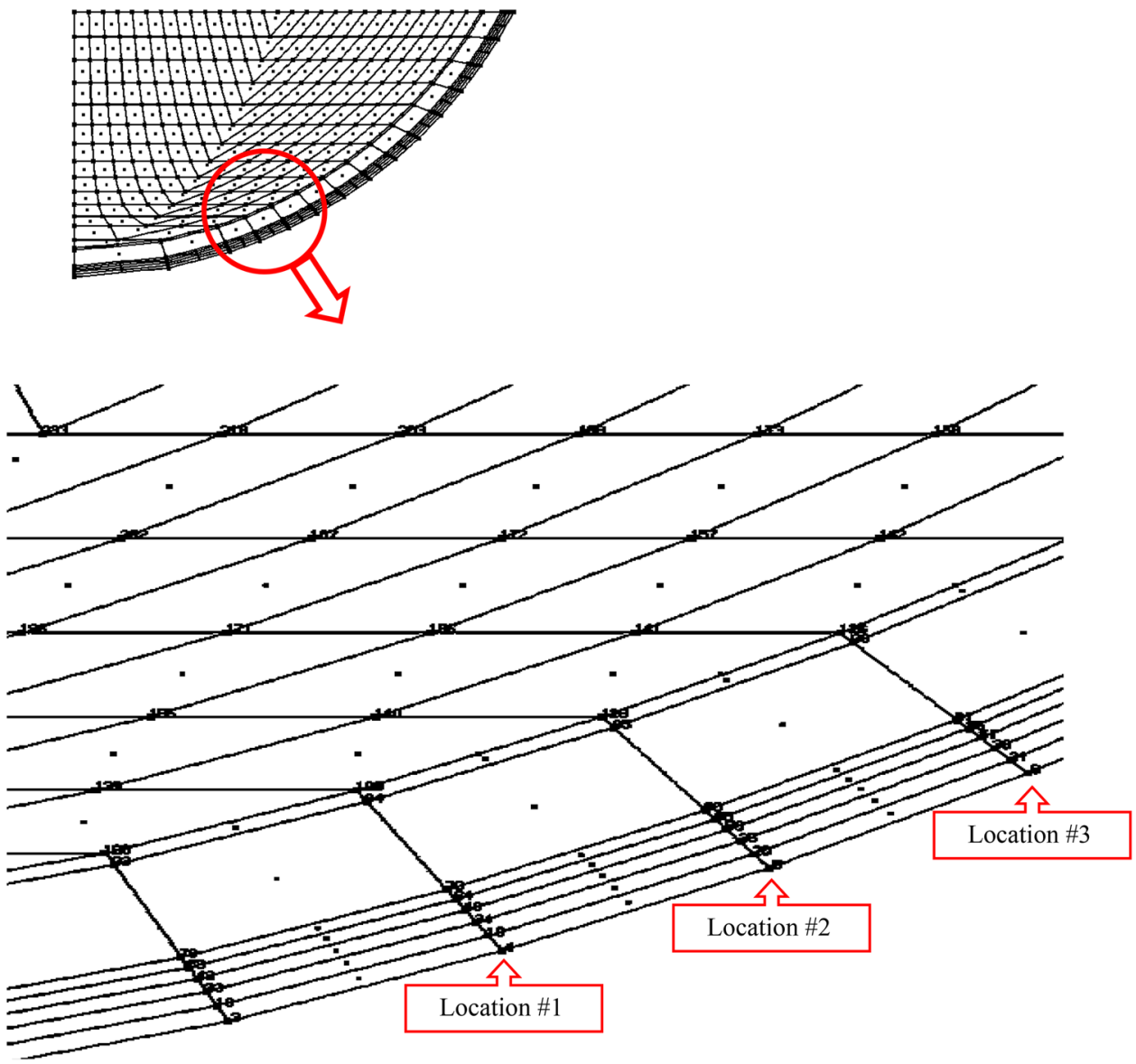

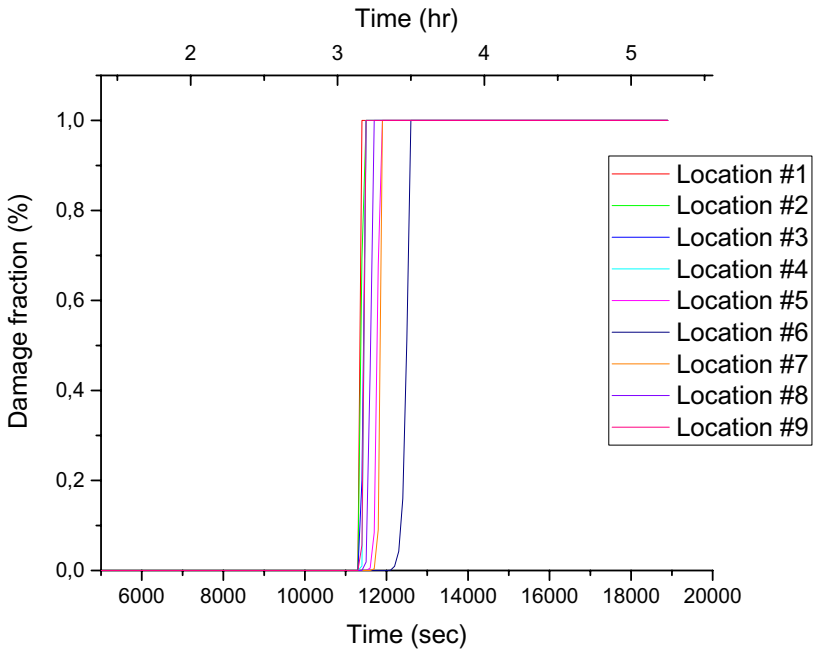

Fig. 16 Damage fraction in the lower head vessel

- The first failure of the RCS pressure boundary is the surge line (hot leg). Due to the flows through the seal leaks, the discharge line which is in direct contact with the pressurizer undergoes these loadings (pressure and temperature), which causes its rupture.

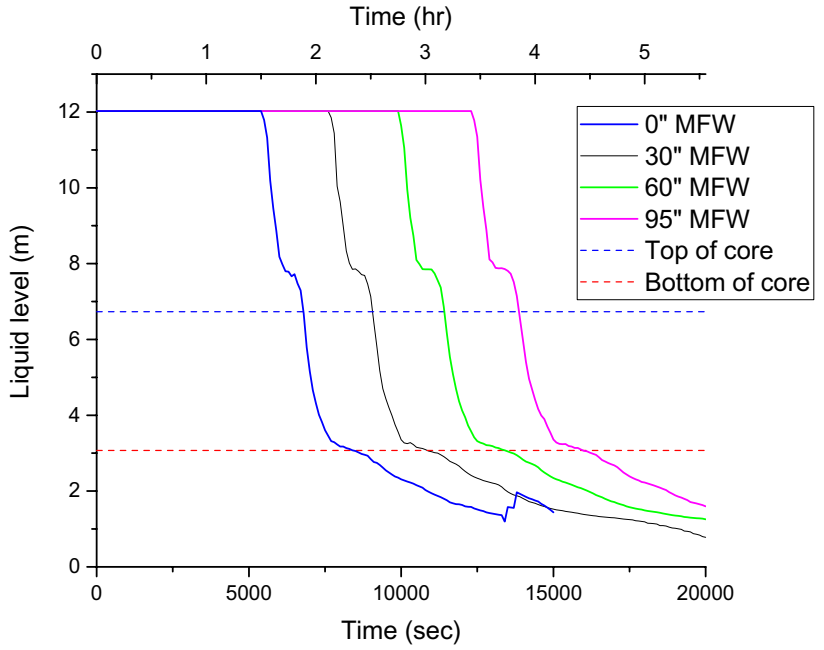

Fig. 17 Reactor vessel collapsed liquid level for scenario \#2

- The only good thing about RCS depressurization that occurs as a result of an initial pressure boundary failure is that it can effectively eliminate the risk of a second failure at any other location in RCS pressure boundary. Accumulator injection will follow, following a rapid RCS 
Table 2 Scenario \#1 accident sequences

\begin{tabular}{|c|c|}
\hline Time (s) & Sequences \\
\hline 0 & $\begin{array}{l}\text { Transient initiation: } \\
\text { Off-site power failure } \\
\text { On-site power failure (diesel generator + battery+AC) } \\
\text { Reactor SCRAM } \\
\text { RCPs tripped } \\
\text { Feedwater pumps tripped } \\
\text { SG isolation valves closed }\end{array}$ \\
\hline & Off-site power failure \\
\hline 6850 & Start of core uncover \\
\hline 8300 & Core fully uncover \\
\hline 8700 & Hydrogen production start \\
\hline 9800 & Creep rupture of the pressurizer surge line starts \\
\hline 11,400 & Creep rupture of the lower head vessel starts (location 1) \\
\hline 11,460 & Core oxidation start \\
\hline 12,600 & Creep rupture of the lower head vessel starts (location 9) \\
\hline 20,000 & End of transient \\
\hline
\end{tabular}

Table 3 Scenario \#2 accident sequences

\begin{tabular}{lcccr}
\hline Sequences & \multicolumn{4}{l}{ AFW delaying (s) } \\
\cline { 2 - 5 } & 0 & 30 & 60 & 95 \\
\hline Transient initiation: & 0 & 0 & 0 & 0 \\
Off-site power failure & & & & \\
On-site power failure & & & & \\
Reactor SCRAM & & & & \\
RCPs tripped & & & & \\
Feedwater pumps tripped & & & & \\
SG isolation valves closed & & & & \\
Start of core uncover & 6850 & 9050 & 11,450 & 13,850 \\
Core fully uncover & 8300 & 10,850 & 13,400 & 15,950 \\
\hline
\end{tabular}

depressurization, providing enough water to cool the core and the RCS piping.

- Maintaining the MFW system for some time; even for a short period of $30 \mathrm{~s}$; delays the core uncovery for $1 \mathrm{~h}$.

Acknowledgements The authors would like to thank the ISS for the use of Surry PWR RELAP5/SCDAPSIM input deck.

\section{Compliance with ethical standards}

Conflict of interest The authors declare that they have no competing interests.

\section{References}

1. Altenbach H, Skrzypek JJ (1999) Creep and damage in materials and structures. Springer, Berlin
2. Brust FW et al (2013) Severe accident condition modeling in PWR environment: creep rupture modeling. In: ASME 2013 pressure vessels and piping conference. American Society of Mechanical Engineers Digital Collection

3. Prošek A, Cizelj L (2013) Long-term station blackout accident analyses of a PWR with RELAP5/MOD3.3. Science and Technology of Nuclear Installations, 2013

4. Vierow K et al (2004) Severe accident analysis of a PWR station blackout with the MELCOR, MAAP4 and SCDAP/RELAP5 codes. Nucl Eng Des 234(1-3):129-145

5. Surry to seek 80-year operation (2016) Nuclear Engineering Internationa, 30 March 2016. Accessed 7 April 2016

6. Knudson DL, Ghan LS, Dobbe CA (1998) SCDAP/RELAP5 evaluation of the potential for steam generator tube ruptures as a result of severe accidents in operating PWRs. Idaho National Laboratory (INL), Idaho Falls

7. Siefken $L$ et al (2000) SCDAP/RELAP5/MOD3.3 Code manual. Vol. 5: assessment of modeling of reactor core behavior during severe accidents. In: NUREG/CR-6150, INEL-96/0422, Idaho National Engineering and Environmental Laboratory

8. Saad D, Hadjam A (2019) Mesh size sensitivity of the simple cheap vessel benchmark problem. J Nucl Energy Sci Power Gener Technol 8:1

9. Siefken LJ et al (1999) SCDAP/RELAP5 modeling of heat transfer and flow losses in lower head porous debris. Idaho National Laboratory (INL), Idaho Falls

10. Dieter GE, Bacon DJ (1986) Mechanical metallurgy, vol 3. McGraw-hill, New York

11. Larson FR (1952) A time-temperature relationship for rupture and creep stresses. Trans ASME 74:765-775

12. Manson SS, Haferd AM (1953) A linear time-temperature relation for extrapolation of creep and stress-rupture data. N.A.C.A. Technical Note 2890

13. Allison C (1997) SCDAP/RELAP5/MOD 3.2 code manual volume II: damage progression model theory. Technical Report NUREG/ CR-6150 INEL-96/0422, Idaho National Engineering and Environmental Laboratory

14. Goldhoff R (1959) Comparison of parameter methods for extrapolating high temperature data. J Basic Eng 81:629-643

15. Orr RL, Sherby OD, Dorn JE (1953) Correlations of rupture data for metals at elevated temperatures. Institue of Engineering Research, University of California, Berkeley

16. Shaukats S, Jackson J, Thatcher D (1991) Regulatory analysis for generic issue 23: reactor coolant pump seal failure. US Nuclear Regulatory Commission, Washington, DC, Report No. NUREG1401 https://inis.iaea.org/search/search.aspx. Accessed 2018

17. Fletcher $C$ et al (2006) Evaluation of uncertanties in SCDAP/ RELAP 5 station blackout simulations. Information Systems Laboratories, Inc., RES-CO5-340

Publisher's Note Springer Nature remains neutral with regard to jurisdictional claims in published maps and institutional affiliations. 